Review Article

\section{Fetal Alcohol Spectrum Disorders - What does it mean?}

\author{
Rajeev Gupta*
}

Consultant, Paediatrician, Barnsley Foundation Hospital, Gawber Road, Barnsley, S75 2EP, UK

Prenatal alcohol exposure is one of the most important causes of preventable cognitive impairment in the world. The developing neurological system is exquisitely sensitive to harm from alcohol and there is now also substantial evidence that alcohol-related harm can extend beyond the individual person, leading to epigenetic changes and intergenerational vulnerability and disadvantage [1].

The adverse effects of alcohol on the developing human comprise a spectrum of structural anomalies and behavioral and neurocognitive disabilities, most accurately termed fetal alcohol spectrum disorders (FASD). FASD continuum includes fetal alcohol syndrome (FAS), partial fetal alcohol syndrome (PFAS), alcohol related birth defects (ARBD), and alcohol related neurodevelopmental disorder (ARND), allowing for more reproducible and accurate FASD diagnosis in a clinical setting [2] and there has been proposal for name change.

Fetal Alcohol Spectrum Disorders (FASD) thus includes a continuum of disorders that occur in children as a result of their mothers' consumption of alcohol during pregnancy. The most severe of these disorders is Fetal Alcohol Syndrome (FAS). FASD presents differently in every child, but all children with FASD have intellectual and/or behavioral impairments [3]. In general, FASD includes a pattern of retarded growth and development, both neuropsychological and physical, with typical facial dysmorphic features, found in some children exposed to alcohol during pregnancy. The signs and symptoms of FASD may include any mix of physical defects, intellectual or cognitive disabilities, and problems functioning and coping with daily life. This is therefore termed Fetal Alcohol Spectrum Disorders (FASD) rather than previous term FAS which is now used only to describe the most severe type of FASD. Some doctors prefer to call it FAE (Fetal Alcohol Effects) for less severe phenotype [2].

A spectrum of physical and neurodevelopmental abnormalities has been attributed to the effects of alcohol on the fetus. Effects seen in a child and the diagnosis reached depend on the duration of exposure to substantial maternal alcohol consumption during pregnancy, the range and timing

\section{More Information}

*Address for Correspondence: Rajeev Gupta,

Consultant, Paediatrician, Barnsley Foundation Hospital, Gawber Road, Barnsley, S75 2EP, UK, Tel: +44 1226432860;

Email: rajeev.gupta@nhs.net

Submitted: 11 March 2020

Approved: 16 March 2020

Published: 17 March 2020

How to cite this article: Gupta R. Fetal Alcoho Spectrum Disorders - What does it mean? Clin J Obstet Gynecol. 2020; 3: 018-020.

DOI: 10.29328/journal.cjog. 1001043

ORCiD: orcid.org/0000-0001-5484-2498

Copyright: (c) 2020 Gupta R. This is an open access article distributed under the Creative Commons Attribution License, which permits unrestricted use, distribution, and reproduction in any medium, provided the original work is properly cited.

\section{Check for updates}

OPEN ACCESS

of peak blood-alcohol levels, the nutritional state of the mother, and individual susceptibility [4]. Interestingly, the level of maternal consumption that produces Fetal Alcohol Spectrum Disorders (FASD) has not been established and is influenced by genetic as well as other maternal and fetal characteristics.

\section{Symptoms}

The manifestations of FASD varies widely. Some children are affected much more than others. Children with less severe phenotypes in the FASD continuum present an even greater diagnostic challenge, because often the physical signs are more subtle. Some manifestations appear early and others appear or recognized quite late. The less severe types of FASD are much more common than FAS, however, and may affect $\geq 1 \%$ of all children born in the United States. The range of alcohol damage during fetal development, from mild to severe, is well documented in the medical literature and may manifest in physical, behavioral and social indices. A fetal alcohol behavior scale have been proposed [5].

Autti-Rämö, et al. [6], has tried to completely clinically characterize the structural and learning/behavioral phenotypes of a large cohort of older children and adolescents with moderate to severe disability within the FASD continuum, however it hasn't been much successful. There is also an attempt to rename and have Revised IOM Diagnostic Criteria and to develop scoring of features, however no consensus 
reached. The most important way of people identify FASD is still clinical. It has a variety of features which can be divided into 3 groups although there is some overlap.

\section{Physical manifestations}

- Unusual facial features ( dysmorphism) - small eyes, thin upper lip, short, upturned nose, smooth philtrum, "Railroad track" ears

- Deformities of joints, limbs and fingers (camptodactyly, "hockey stick" or other altered palmar creases)

- Small head circumference and brain size

- Congenital heart defects

- Intrauterine growth retardation and slow postnatal growth

- Vision difficulties (refractive errors, strabismus)

- Hearing problems

- Dental crowding, nail hypoplasia, GU anomalies

\section{Developmental and cognitive problems}

- learning disorders and delayed development

- communication and speech difficulties (speaking too much and/or too fast and interrupting others)

- Abnormalities in memory, language, motor, and visuospatial abilities

- motor dysfunction (difficulty playing sports)

- Poor coordination or balance

- Trouble with attention and with processing information

- Difficulty with reasoning

- Lower level of problem-solving

- Difficulty identifying consequences of choices

- Poor judgment skills

- Rapidly changing moods

- difficulties in personal manner (eg., clumsiness, disorganization, and losing or misplacing things)

- poor academic performance (eg., poor attention span and difficulty completing tasks)

- unusual physiologic responses (eg., hyeracusis, hyperactivity, and sleep disturbances)

\section{Behavioural and social issues}

Problems in functioning, coping and interacting with others may include:
- emotional lability (rapid mood swings and overreacting)

- Difficulty getting along with other children

- Deficient social interactions (lack of awareness of consequences of behavior and poor judgment)

- Trouble adapting to change or switching from one task to another

- Problems with behavior and impulse control

- Poor concept of time

- Problems staying on task

- Difficulty planning or working toward a goal

- School and family integration problems

- ADHD

An excess of psychopathology, (including hyperkinetic disorders, emotional disorders, sleep disorders, and abnormal habits and stereotypes) with a strong persistence over time was found $[7,8]$.

In a study specifically designed to look for the effects on Developmental Behavior, there were significant differences ( $p=0.01$ ) between the groups on five of six subscales of the Developmental Behavior Checklist (DBC) with controls scoring lower on the disruptive, self-absorbed, anxiety, antisocial behavior, and communication disturbance scales. The DBC profiles of the two foetal alcohol exposed groups did not differ in FAS and FAE or age- and sex-matched control children with unspecific intellectual disability [8]. ADHD children were 2.5 times more likely to be exposed to alcohol in utero [9].

\section{What happens to the brain}

There may be no visible change in the brain images in FASD, however in a study MRI and single photon emission computed tomography (SPECT) to find specific areas of abnormality showed that morphological anomalies were situated both cortically and subcortically. The abnormalities included cortical atrophy, dilated ventricle, corpus callosum hypoplasia, cerebellar atrophy etc. Delayed myelination of the white matter was seen in two patients. Volumetric studies of the hippocampus showed morphological left-right asymmetry in five of eight patients. SPECT showed mild hypo perfusion of the left hemisphere and a negative left-right index was located especially in the left parietooccipital region, i.e. in the brain areas implicated in arithmetical and logical-grammatical functions, which are known to be affected in FAS. Normal leftright dominance was also lacking in the frontal area, i.e. the brain area affected in attention-deficit-hyperactivity disorder (ADHD). Detection of these abnormalities, although they are not unique to FASD, may be helpful in the diagnosis and any attempts at rehabilitation [10]. 


\section{What to do if you suspect FASD}

If you're pregnant and suspect that you have difficulty to stop drinking, ask your obstetrician, primary care doctor or mental health professional for help early. They can assess and provide help or point in the right direction. Since early diagnosis may help reduce the risk of long-term problems for children with fetal alcohol syndrome, an early discussion or advice from a pediatrician may also be helpful.

If you have adopted a child or are providing foster care, you may not know if the biological mother drank alcohol while pregnant, and it may not initially occur to you that your child may have FASD or fetal alcohol syndrome. It is better to express your suspicion, specially, if the child has problems with learning and behavior.

\section{References}

1. Oei JL. Alcohol use in pregnancy and its impact on the mother and child. Addiction. 2020.

PubMed: https://www.ncbi.nlm.nih.gov/pubmed/32149441

2. Hoyme HE, May PA, Kalberg WO, Kodituwakku P, Gossage JP, et al. A practical clinical approach to diagnosis of fetal alcohol spectrum disorders: clarification of the 1996 institute of medicine criteria Pediatrics. 2005; 115: 39-47.

PubMed: https://www.ncbi.nlm.nih.gov/pubmed/15629980

3. Wilhoit LF, Scott DA, Simecka BA. Fetal Alcohol Spectrum Disorders: Characteristics, Complications, and Treatment. Community Ment
Health J. 2017; 53: 711-718.

PubMed: https://www.ncbi.nlm.nih.gov/pubmed/28168434

4. Autti-Rämö I. Foetal alcohol syndrome - a multifaceted condition. Dev Med Child Neurol. 2002; 44: 141-144.

PubMed: https://www.ncbi.nlm.nih.gov/pubmed/11848112

5. Streissguth AP, Bookstein FL, Barr HM, Press S, Sampson PD. A fetal alcohol behavior scale. Alcohol Clin Exp Res. 1998; 22: 325-333. PubMed: https://www.ncbi.nlm.nih.gov/pubmed/9581636

6. Autti-Rämö I, Fagerlund A, Ervalahti N, Loimu L, Korkman M, et al. Fetal alcohol spectrum disorders in Finland: clinical delineation of 77 older children and adolescents. Am J Med Genet A. 2006; 140: 137-143. PubMed: https://www.ncbi.nlm.nih.gov/pubmed/16353236

7. Steinhausen HC, Spohr HL, Long-term outcome of children with fetal alcohol syndrome: psychopathology, behavior, and intelligence. Alcohol Clin Exp Res. 1998; 22: 334-338.

PubMed: https://www.ncbi.nlm.nih.gov/pubmed/9581637

8. Steinhausen HC, Willms J, Metzke C, Spohr H. Behavioural phenotype in foetal alcohol syndrome and foetal alcohol effects. Dev Med Child Neurol. 2003; 45: 179-182.

PubMed: https://www.ncbi.nlm.nih.gov/pubmed/12613774

9. Hart H. Case-control study of attention-deficit hyperactivity disorder and maternal smoking, alcohol use, and drug use during pregnancy. $\mathrm{J}$ Am Acad Child Adolesc Psychiatry. 2002; 41: 378-385. PubMed: https://www.ncbi.nlm.nih.gov/pubmed/11931593

10. Riikonen R, Salonen I, Partanen K, Verho S. Brain perfusion SPECT and MRI in foetal alcohol syndrome. Dev Med Child Neurol. 1999; 41: 652659.

PubMed: https://www.ncbi.nlm.nih.gov/pubmed/10587040 